\title{
Continuous photometric observations at ENEA base in Lampedusa to estimate precipitable water
}

\author{
Renato Santangelo, Sergio Pugnaghi, Stefano Corradini, Luca Lombroso and Sergio Teggi \\ Dipartimento di Ingegneria dei Materiali e dell'Ambiente (Osservatorio Geofisico), \\ Università di Modena e Reggio Emilia, Modena, Italy
}

\begin{abstract}
Water vapour is a variable component of the atmosphere both in space and time. It is one of the most important components because of its effects in many fields: Meteorology, Climatology, Remote Sensing, Energy-Budget, Hydrology, etc. This work compares radiometric (sun photometer) readings, Global Positioning System (GPS) data and a meteorological model forecasted data. The aim is to understand if GPS measurements may help Numerical Weather Prediction (NWP) models. It is well known that GPS measurements are affected by the so-called tropospheric delay. Part of it, the so-called wet delay is related mainly to the amount of water vapour along the path of the GPS signal through the troposphere. Precise knowledge of the abundance of water vapour, in space and time, is important for NWP model because water vapour is the predecessor of precipitation. Despite the high variability of water vapour compared to other meteorological fields, like pressure and wind, water vapour observations are scarce, so that additional measurements of water vapour are expected to benefit meteorology. A new sun photometer, which is part of the AERONET (AErosol and RObotic NETwork) program, has been installed at the ENEA (Ente per le Nuove tecnologie, l'Energia e l'Ambiente) base of Lampedusa Island. The sun photometer is quite close (less then $4 \mathrm{~km}$ ) to an ASI (Agenzia Spaziale Italiana) GPS permanent receiver. A long record (summer period of the year 2000) of sun photometric measurements is available for the station at Lampedusa. We found that the GPS and sun photometric data are better correlated (std. dev. about $10 \mathrm{~mm}$ for the wet delay) than are the GPS measurements with the NWP model predictions. This is an indication that GPS delay data may contain information useful for weather prediction.
\end{abstract}

Key words water-vapour - aerosols - GPS - sunphotometer-NWP-model

\section{Introduction}

Water vapour is a highly variable component of the atmosphere and plays a crucial role in many atmospheric phenomena (see all Emanuel

Mailing address: Dr. Renato Santangelo, Dipartimento di Ingegneria dei Materiali e dell'Ambiente (Osservatorio Geofisico), Università degli Studi di Modena e Reggio Emilia, Via Vignolese 905, 41100 Modena, Italy; e-mail: santangelo.renato@unimo.it et al., 1995; Dabberdt and Schlatter, 1996). Water vapour is itself a major greenhouse gas, but it also takes part in the formation of aerosols affecting in different ways the energy budget of the atmosphere (Russel et al., 1999). Water vapour is a key variable in atmospheric motions on a wide range of scales and the lack of water vapour observations, both temporal and spatial, is one of the problems in NWP models; in particular for clouds and precipitation (Binder and Schär, 1996). In space geodesy, water vapour is seen as a source of error (Dodson et al., 1996), as fluctuations of the tropospheric water vapour content produce spatial and temporal variations of the refraction properties of the troposphere. 
The Integrated Water Vapour (IWV), also called, the Precipitable Water (PW), is the mass per area of water vapour contained in an atmospheric vertical column. It is often converted to a thickness, in which case $1 \mathrm{~kg} / \mathrm{m}^{2}$ corresponds to $1 \mathrm{~mm}$ of PW. The precipitable water is usually derived from the atmospheric radiosoundings; it is the integral of the absolute humidity $\rho_{v}$ (or water vapour density) along the vertical direction $z$ or the integral, using the atmospheric pressure as the vertical coordinate, of the specific humidity $q$ (the density of the water vapour relative to the total density of the air). Alternatively, the precipitable water can be estimated using a microwave radiometer (England et al., 1993), or using solar transmittance methods (Ingold et al., 2000).

This paper compares three different integrated water vapour estimates. This work derives from the research activities performed by different teams in the framework of the EUfunded MAGIC (Meteorological Applications of GPS Integrated Column Water Vapour Measurements in the Western Mediterranean) project. For further information about MAGIC and the data in the MAGIC data sample, see http:// www.acri.fr/magic/index.html. The three types of data we compare are from GPS measurements, sun photometric readings, and from forecast data produced running the meteorological model HIRLAM. To distinguish the HIRLAM and the sun photometer water vapour estimates: IWV and PW respectively have been used in the following.

The MAGIC project utilised the data of about 40 GPS-sites, mainly in Spain, France and Italy; in this paper the permanent ASI station of Lampedusa (a small and flat island located between Tunisia and Italy: Sicilian Channel) is considered. No meteorological measurements are available at the GPS site (Capitaneria di Porto).

\section{ZTD and PW estimations}

In the MAGIC project (Haase et al., 2001), the Zenith Total Delay (ZTD) rather than the precipitable water is used as the key GPS tropospheric measure. ZTD is the atmospheric measurement provided by the GPS processing software. ZTD is the sum of two components, the Zenith Hydrostatic (or dry) Delay (ZHD) and the Zenith Wet Delay (ZWD) (see eqs. (2.1) and (2.2) for definitions).

$$
\begin{gathered}
\mathrm{ZHD}=\int_{0}^{p_{s}} \frac{R_{d}}{g} \cdot k_{1} \cdot d p \\
\mathrm{ZWD}=\int_{0}^{p_{s}} \frac{R_{d}}{g \cdot \varepsilon} \cdot q \cdot\left[\left(k_{2}-k_{1} \cdot \varepsilon\right)+\frac{k_{3}}{T}\right] d p
\end{gathered}
$$

$q$ is the specific humidity; $p_{s}$ is the surface pressure; $R_{d}=287.04\left(\mathrm{~J} \mathrm{~kg}^{-1} \mathrm{~K}^{-1}\right)$ is the gas constant for the dry air; $g$ is the acceleration due to gravity and non inertial forces acting upon a particle at rest with respect to the Earth; $\varepsilon=M_{v} / M_{d} \approx 0.622$ is the ratio of the molecular weight of the water vapour $\left(M_{v}\right)$ relative to the molecular weight of the dry air $\left(M_{d}\right) ; T$ is the air temperature and finally: $k_{1}=7.7610^{-7}(\mathrm{~K} / \mathrm{Pa})$, $k_{2}=7.0410^{-7}(\mathrm{~K} / \mathrm{Pa}), k_{3}=3.7410^{-3}\left(\mathrm{~K}^{2} / \mathrm{Pa}\right)$ are empirical constants (Bevis et al., 1994).

ZHD is mainly a function of surface pressure, which may be obtained either from a barometer at the GPS site or from a meteorological model. Most of the GPS sites of the proper type are set-up for geodetic purposes and not equipped with extra instruments like barometers. ZWD is related to $\mathrm{PW}$, the precise conversion factor requires knowledge about the temperature profile of the atmosphere (Askne and Nordius, 1987), which may come from a meteorological model or radio sonde observations valid at the time of the measurement. Alternatively a more approximate conversion factor, based on empirically derived relations, may be used. The scale factor between PW and ZWD empirically determined by Bevis et al. (1992) is 0.15.

At all the Italian ASI-GPS stations the data analysis is done using GIPSY-OASIS II (Webb and Zumberge, 1997) software with the Precise Point Positioning (Zumberge et al., 1997) mode. ASI ZTD products are available on a daily basis and with a delay of 15 days, through anonymous ftp on ftp://geodaf.mt.asi.it. The results described in the following have been obtained using all the available data (for the considered station) pertaining to the year 2000; the time step is $15 \mathrm{~min}$. 
The High Resolution Limited Area Model (HIRLAM) is an NWP model developed jointly by a number of European meteorological institutes. In particular, this model uses a so-called hybrid coordinate in the vertical (i.e. not directly related to altitude or atmospheric pressure); it has 31 levels, from the surface up to about $10 \mathrm{hPa}$. As boundaries for the HIRLAM model analyses and short range forecast were used from the global model run at the European Centre for Medium Range Weather Forecasts (ECMWF). For the purpose of MAGIC a special domain, centred on the Mediterranean Sea was utilised. For each MAGIC GPS location HIRLAM provides, using eqs. (2.1) and (2.2), the ZTD, the ZWD, the Integrated Water Vapour (IWV) and the surface pressure; these quantities are provided both at the HIRLAM surface and at the altitude of the GPS antenna. Furthermore the $2 \mathrm{~m}$ temperature and the relative humidity are provided at the HIRLAM surface.

A sun photometer is an instrument that measures the direct solar irradiance at the Earth's surface. The measurements are taken at chosen wavelengths in the visible and near infrared part of the electromagnetic spectrum to determine the atmospheric transmission and
Table I. Sun photometer nominal centre wavelengths.

\begin{tabular}{lccccc}
\hline \hline Channel\# & 1 & 2 & 3 & 4 & 5 \\
Wavelenght (nm) & 1020 & 870 & 670 & 440 & 936 \\
\hline
\end{tabular}

scattering properties. The sun photometer used in this study is the model CE-318 produced by Cimel Electronique (France). Like all sun photometers of this type, it has the same main set of filters (see table I), plus three added filters not described here. All the filters have a bandwidth of $10 \mathrm{~nm}$. Sun photometer like CE-318 provides the water vapour transmittance from measurements in spectral channel $(936 \mathrm{~nm})$ and in adjacent channels $(870 \mathrm{~nm}$ and $1020 \mathrm{~nm}$ ). The problem is then to convert the water vapour transmittance into precipitable water. The first attempts to quantify the PW from water vapour absorption in the near infrared date back to 1912 , but this subject continues to be studied (Ingold et al., 2000; Schmid et al., 2001). Figure 1 shows (thick line) the water vapour transmittance in the range 700-1100 nm computed using the MODTRAN3.5 code (Kneizys et al., 1996) (assuming a mid latitude summer atmosphere) with a spectral resolution of $50 \mathrm{~cm}^{-1}$ (i.e. about $5 \mathrm{~nm}$, depending

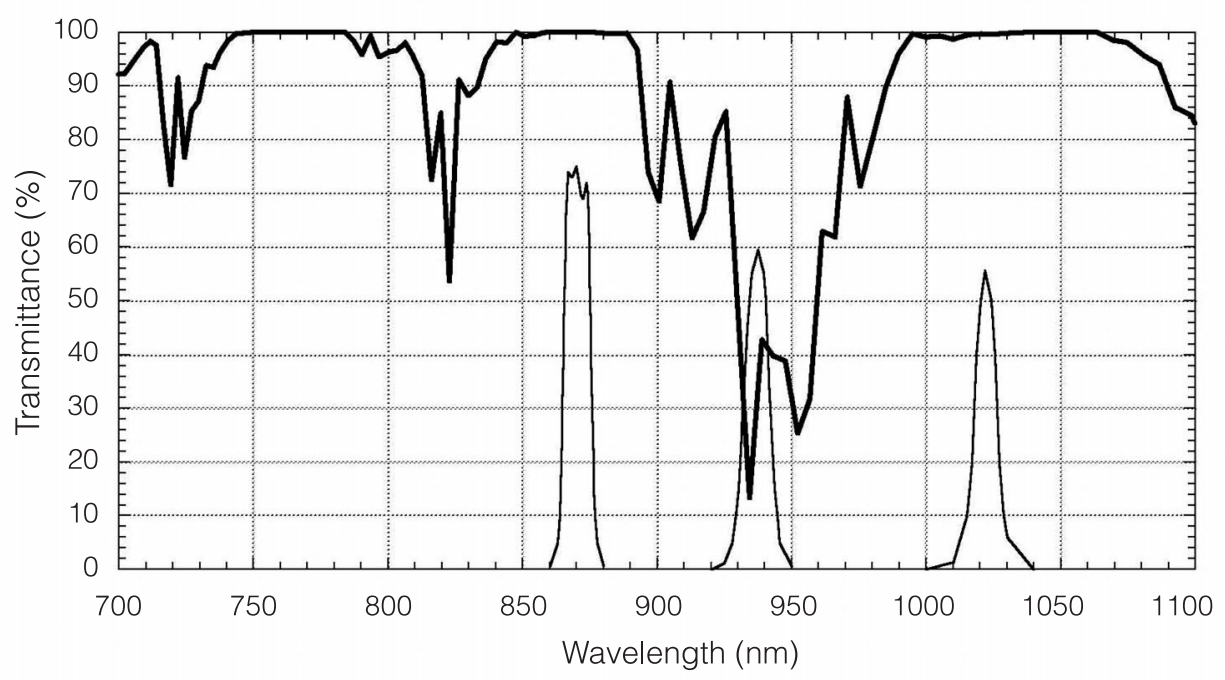

Fig. 1. MODTRAN midlatitude summer water vapour transmittance (thick line) and 870, 936, $1020 \mathrm{~nm}$ filter response functions (thin line). 
on wavelength); the $0.72,0.82$ and 0.94 microns water vapour absorption bands are visible. Together with the water vapour transmittance, the spectral transmittance of the $936 \mathrm{~nm}$ and the two adjacent filters $(870 \mathrm{~nm}$ and $1020 \mathrm{~nm})$ are shown in fig. 1 (thin line). The 870 and $1020 \mathrm{~nm}$ channels (window channels) are located outside of molecular absorption bands (the water vapour bands shown on the figure and the oxygen band located at about $0.76 \mu \mathrm{m}$, not shown); they are usually used to determine the Aerosol Optical Thickness (AOT). For the $0.94 \mu \mathrm{m}$ water vapour band the Bouguer's (Lambert, Beer) law (used to compute AOT) is not valid since it is valid for monochromatic radiation only (see fig. 1). Equation (2.3) is the equation used for the three quoted channels. In this equation $J_{\lambda}$ is the sun photometric measurement (instrumental units) and represents the normal solar irradiance at the surface, $J_{0, \lambda}$ represents the normal solar irradiance at the top of the atmosphere at the mean Sun-Earth distance (instrument calibration constant), $R$ is the square of the inverse of the Sun-Earth distance in astronomical units, $m=\int \rho \cdot d s / \int \rho \cdot d z$ is the relative optical airmass ( $s$ is the slant path of the solar ray, $z$ is the vertical path) to compute $m$ the AERONET protocol uses the Kasten and Young formula (1989), $\tau_{\lambda}=\tau_{\lambda}^{R}+\tau_{\lambda}^{A}$ is the total optical thickness corresponding to the sum of the molecular (Rayleigh) and aerosol optical thickness, finally $T_{\lambda}^{w}$ is the water vapour transmittance.

$$
J_{\lambda}=R \cdot J_{0, \lambda} \cdot e^{-m \cdot \tau_{\lambda}} \cdot T_{\lambda}^{w}
$$

In the window channels, the water vapour transmittance is equal to one so eq. (2.3) enables us to compute AOT (the Rayleigh optical depth is known). The interpolation at $936 \mathrm{~nm}$ of the AOT values obtained for the adjacent window channels permits us to estimate, again using eq. (2.3), the water vapour transmittance. The relationship used to estimate the PW from the water vapour transmittance is (Halthore et al., 1997)

$$
T^{w}=e^{-a \cdot w^{b}} .
$$

Where the two constants $a$ and $b$ are related to the considered channel and $w=m$ PW.

\section{Results}

Figure 2 shows the difference between the zenith total delay estimated from HIRLAM at the GPS antenna altitude and the value obtained from the GPS measurement. The ZTD mean difference (HIRLAM-GPS) is $-11.8 \mathrm{~mm}$ and the standard deviation $22.4 \mathrm{~mm}$.

The HIRLAM zenith wet delay is obtained using eq. (2.2). The GPS zenith wet delay is obtained subtracting the HIRLAM zenith hydrostatic delay, computed from eq. (2.1), using the HIRLAM surface pressure estimated at the antenna altitude. The ZTD differences shown in fig. 2 have the same variability as the ZWD (not reported). That is to say that the hydrostatic delay is well computed from the estimated surface pressure. The mean and standard deviation of the ZWD differences (HIRLAM-GPS) are exactly the same values (reported above) for the ZTD.

The IWV is computed from the HIRLAM atmospheric profile (above the GPS site). The same quantity is derived from the sun photometric measurement inverting eq. (2.4). The sun photometric PW data show values higher than the IWV estimated by the HIRLAM model; the mean systematic difference is about $10-15 \%$.

On the basis of the recent literature (Callies et al., 2000; Giver et al., 2000; Schmid et al., 2001), the reason for this difference seems due to the underestimated $\mathrm{H}_{2} \mathrm{O}$ absorption line intensities used to date (HITRAN database). According to Giver et al. (2000), a $14.4 \%$ increase in the line strengths for the $0.94 \mu \mathrm{m}$ band is suggested; this would mean an $8-13 \%$ decrease (depending on the considered atmospheric radiative transfer model) in the sun photometric PW estimates (Schmid et al., 2001). Schmid et al. (2001) suggest, in particular during the period with high PW, to use the following eq. (3.1) instead of eq. (2.4)

$$
T^{w}=e^{-a \cdot w^{b-\beta \cdot w}} .
$$

The HIRLAM data of year 2000, for Lampedusa and also for others considered stations results in a ratio between IWV and ZWD of about 0.16 (i.e. $1 \mathrm{~mm}$ of IWV corresponds to about $6.3 \mathrm{~mm}$ of zenith wet delay). The calibration constants of the 


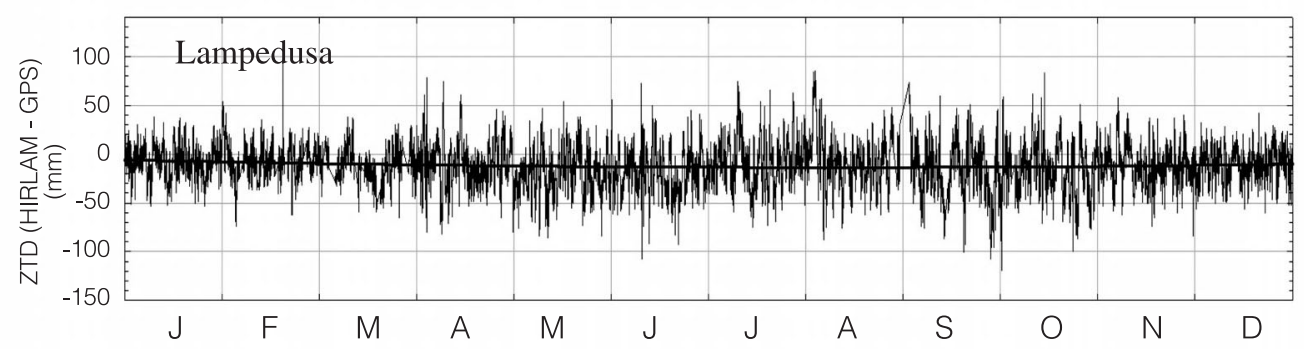

Fig. 2. (HIRLAM - GPS) ZTD differences.

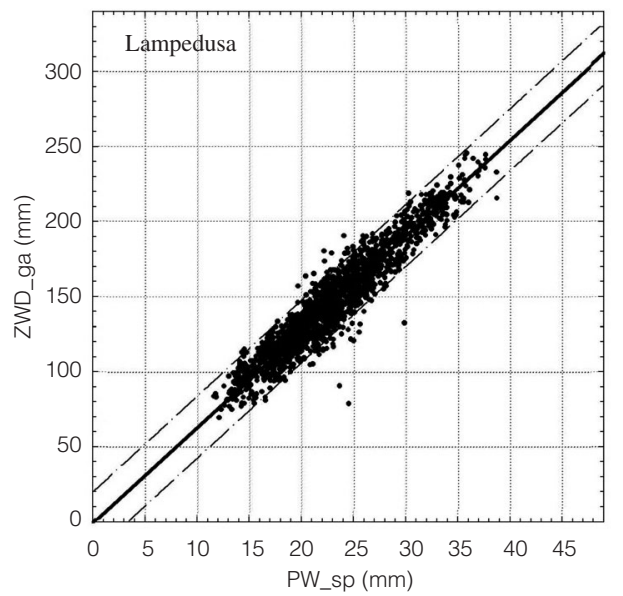

Fig. 3. GPS ZWD and sun photometer PW scatter plot.

sun photometers have been modified to account for this factor between PW and ZWD.

Figures 3 and 4 are the scatter plots of the GPS ZWD versus the PW sun photometric readings and the HIRLAM IWV estimates respectively. The standard deviation of the difference between the ZWD estimated using the linear regression shown in the two scatter plot are $10.5 \mathrm{~mm}$ (sun photometer) and $26.9 \mathrm{~mm}$ (HIRLAM). The confidence interval indicated in the figs. 3 and 4 is $95 \%$ (i.e. $2 \mathrm{SD}$ ).

\section{Conclusions}

One year of forecasted (each $15 \mathrm{~min}$ ) vertical atmospheric profiles at the GPS site of Lampe-

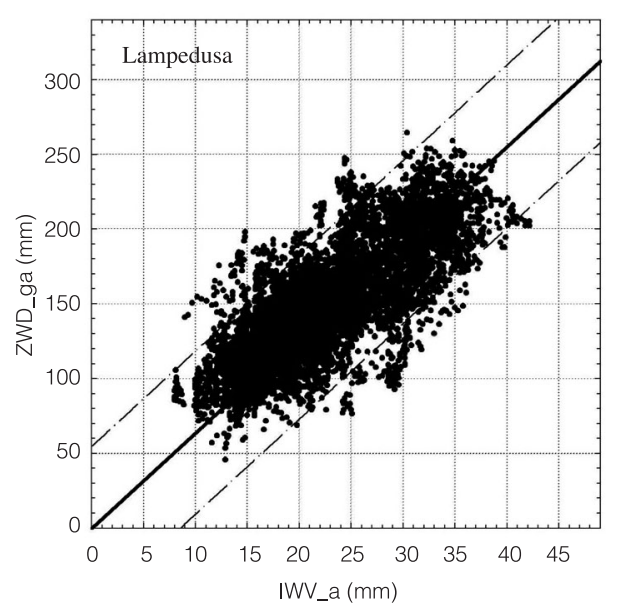

Fig. 4. GPS ZWD and HIRLAM IWV scatter plot.

dusa and one year of GPS data were considered and the ZTD computed. The IWV was computed using the HIRLAM forecasted profiles. Three months of sun photometric measurements in Lampedusa are available and were considered.

The pressure forecast by HIRLAM for Matera agrees very well with local pressure measurements (test not shown here); this is important because the GPS ZWD was obtained subtracting from the GPS ZTD the HIRLAM $\mathrm{ZHD}$, for which the predicted pressure at the antenna altitude was used. The results are similar for forecasts of age 0-6 and 6-12 h.

The PW sun photometric results are systematically higher than the HIRLAM IWV. This is likely due to a spectroscopic problem, which results in a calibration problem (Schmid et al., 
2001). Nevertheless, the sun photometric PW data correlate more strongly with the GPS ZWD data than with the HIRLAM IWV, indicating that such measurements contain information not fully known by the NWP model. For the HIRLAM results it should be noted that Lampedusa is a very small island (10 km long and $4 \mathrm{~km}$ wide); this means that it is not well resolved by the HIRLAM model (spatial resolution 0.3 deg.), which could explain the large scatter found for the HIRLAM ZWD to GPS measurements (fig. 4).

The reported standard deviation of about 10 $\mathrm{mm}$ agrees with many other experimental results performed with different instruments in different regions (Westwater et al., 1998, 2000; Betti et al., 2000; Pacione et al., 2000; Schmid et al., 2001; Vedel et al., 2001).

The next problem is to understand how the GPS PW or ZTD estimates can be well assimilated into NWP models and to study whether such data improve the forecasts, for example by a better prediction of local, severe rainfall. Such work is under way in- and outside the MAGIC project (Cucurul et al., 2001; Haase et al., 2001).

\section{Acknowledgements}

This work was supported in part by the EC DGXII Environment and Climate RTD Project MAGIC (ENV4-CT98-0745).

The sun-photometer is part of AERONET and we thank NASA for the instrument calibration and in particular Brent Holben for his suggestions.

We thank ENEA (Ente per le Nuove tecnologie, l'Energia e l'Ambiente - Divisione Ambiente Globale e Mediterraneo) for their hospitality in the new base of Lampedusa.

\section{FREFERENCES}

ASKNE, J. and H. NORDIUS (1987): Estimation of tropospheric delay for microwaves from surface weather data, Radio Sci., 22, 379-386,

Betti, B., R. Prini, V. Tornatore, M. Crespi, S. Di PaOla, V. BAIOCChi, F. Radicioni, P. BASIli, S. BonAFOni, R. FERrARA, P. CiOTTI and E. FIONDA (2000): Determinazione del contenuto di vapour acqueo precipitabile con misure GPS in reti locali e misure radiometriche: primi confronti, in Atti della $4 a$ Conferenza Nazionale ASITA, Genova, 3-6 Ottobre 2000, vol. 1, 453-461.

Bevis, M., S. Businger, T.A. Herring, C. Rocken, R.A. ANTHES and R.H. WARE (1992): GPS meteorology: remote sensing of the atmospheric water vapour using the global positioning system, J. Geophys. Res., 97, 15,787-15,801.

Bevis, M., S. Businger, S. Chiswell, T.A. Herring, R.A. ANTHES, C. Rocken and R.H. WARE (1994): GPS meteorology: mapping zenith wet delays into precipitable water, J. Appl. Meteorol., 33, 379-386.

BINDER, P. and C. SCHÄR (Editors) (1996): The Mesoscale Alpine Programme MAP: Design Proposal, Second Edition, pp. 77 (available from MAP Programme Office, c/o Swiss Meteorological Institute, CH - 8044 Zürich, http://www.map.ethz.ch/proposal.html).

CALLIES, J., M. EISINGER, R. SCHERMAUL, R.M. LEARNER, D.A. Newnham, J. Ballard, J. Tennyson and M. WiCKETT (2000): New results of water vapour spectroscopic measurements in the visible and nearinfrared, ESA, EOQ, 67, 1-4.

CUCURULl, L., J. VILA and A. RIUS (2001): Zenith total delay study of a mesoscale convective system: GPS observations and fine-scale modeling, Tellus, 54A, 138-147.

DABBERDT, W.F. and T. W. SCHLATTER (with contributions from the rest of PDT-2) (1996): Research opportunities from emerging atmospheric observing and modeling capabilities, Bull. Am. Meteorol. Soc., 77, 305-323.

Dodson, A.H., J. SHARDLOW, L.C.M. HuBBARD, G. ElGERED and P.O.J. JARLEMARK (1996): Wet tropospheric effects on relative GPS height determination, J. Geod., 70, 188-202.

Emanual, K., D. Raymond, A. Betts, L. Bosart, C. Bretherton, K. Droegemeier, B. Farrell, J. M. Fritsch, R. Houze, M. Le Mone, Douglas Lilly, R. Rotunno, M. Shapiro, R. SMith and A. Thorpe (1995): Report of the first prospectus development team of the U.S. weather research program to NOAA and the NSF, Bull. Am. Meteorol. Soc., 76, 1194-1208.

ENGLAND, M.N., F.J. SCHMIDLIN and J.M. JOHANSSON (1993): Atmospheric moisture measurements: a microwave radiometer-radiosonde comparison, IEEE Trans. Geosci. Remote Sens., 31, 389-398.

GiVER, L.P., C. CHACKERIAN, JR. and P. VARANASI (2000): Visible and near-infrared $\mathrm{H}_{2} \mathrm{O}$ line intensity corrections for HITRAN-96, J. Quant. Spectrosc. Rad. Transfer, 66, 101-105.

HaAse, J., E. Calais, J. Talaya, A. Rius, F. Vespe, R. Santangelo, X.-Y. Huang, J.M. Davila, M. GE, L. Cucurull, A. Flores, C. Sciaretta, R. Pacione, M. Boccolari, S. Pugnaghi, H. Vedel, K. Mogensen, X YANG and J. GARATE (2001): The contributions of the MAGIC project (Meteorological Applications of GPS Integrated Column Water Vapor Measurements in the Western Mediterranean) to the COST 716 objectives of assessing the operational potential of ground-based GPS meteorology on an international scale, Phys. Chem. Earth, 26 (6-8), 433-437.

Halthore, R.N., T.F. ECK, B.N. Holben and B.L. 
MARKHAM (1997): Sunphotometric measurements of atmospheric water vapour column abundance in the 940-nm band, J. Geophys. Res., 102, 4343-4352.

Ingold, T., B. SCHMid, C. MATZLeR, P. DemOUlin and N. KAMPFER (2000): Modeled and empirical approaches for retrieving columnar water vapour from solar transmittance measurements in the $0.72,0.82$, and 0.94 $\mu \mathrm{m}$ absorption bands, J. Geophys. Res., 105 (D19), 24,327-24,343.

KAsten, F. and A.T. Young (1989); Revised optical air mass tables an approximation formula, Appl. Opt., 29, 4735-4738.

KNEIZYS, F.X., D.C. Robertson, L.W. ABREU, P. ACHARYA, G.P. ANDERSON, L.S. ROTHMAN, J.H. CHETWYND, J.E.A. Selby, E.P. Shettle, W.O. Gallery, A. Berk, S.A. ClOUGH and L.S. BERNSTEIN (1996): The MODTRAN 2/3 Report and LOWTRAN 7 MODEL, PL/GPOS, Phillips Lab., Geophysics Directorate, Hanscom AFB, Mass.

Pacione, R., C. Sciaretta, F. Vespe, C. FACCANi, R. Ferretti, E. Fionda, C. FERraro and A. NARDi (2000): GPS meteorology: validation and comparison with ground-based microwave radiometer and mesoscale model for the Italian GPS permanent stations, Phys. Chem. Earth, 26 (3), 139-145.

Russell, P.B., P.V. HoBBS and L.L. STOWE (1999): Aerosol properties and radiative effects in the United States mid-Atlantic haze plume: an overview of Tropospheric Aerosol Radiative Forcing Observational Experiment (TARFOX), J. Geophys. Res., 104, 2213-2222.
SCHMID, B., J.J. MiCHALSKY, D.W. SLATER, J.C. BARNARD, R.N. Halthore, J.C. LilJEGREN, B.N. HOLBEN, T.F. ECK, J.M. LIVINGSTONE, P.B. RuSSELL, T. INGOLD and I. SLUSTKER (2001): Comparison of columnar watervapour measurements from solar transmittance methods, App. Optics, 40 (12), 1886-1896.

Vedel, H., K.S. Mogensen and X.-Y. HuAng (2001): Calculation of zenith delays from meteorological data, comparison of NWP model, radiosonde and GPS delays, Phys. Chem. Earth, 26A, 497-502.

WEBB, F.H. and J.F. ZUMBERGE (1997): An Introduction to GIPSY/OASIS-II, Jet Propulsion Laboratory, California Institute of Technology, D-11088.

WESTWATER, E.R., Y. HAN, S.I. GUTMAN and D.E. WOLFE (1998): Remote sensing of total precipitable water vapor by microwave radiometers and GPS during the 1997 water vapor intensive operating period, in 1998 IEEE International Geoscience and Remote Sensing Symposium Proceedings, Seattle, U.S.A., IV, 2158-2161.

Westwater, E.R., B.B. Stankov, Y. Han, J.A. Shaw, C.N. Long, B.M. Lesht and J. Shannaho (2000): Comparison of microwave radiometers and radiosondes during the Nauru-99 experiment, in 2000 IEEE International Geoscience and Remote Sensing Symposium Proceedings, Seattle, Honolulu, U.S.A.

ZUMBERGE, J.F., M.B. HEIN, D.C. JEFFERSON, M.M. WATKINS and F.H. WEBB (1997) Precise point positioning for the efficient and robust analysis of GPS data from large networks, J. Gephys. Res., 102 (B3), 5005-5017. 